\title{
ALOKASI OPTIMUM DAN WILAYAH PENGEMBANGAN PERIKANAN BERBASIS ALAT TANGKAP POTENSIAL DI TELUK JAKARTA
}

\author{
The Optimum Allocation and Fishery Development Area Based on Potential \\ Fishing Gear in Jakarta Bay
}

Oleh:

\author{
Siti Radarwati ${ }^{*}$, Mulyono S. Baskoro², Daniel R. Monintja², dan Ari Purbayanto² \\ ${ }^{1}$ PT Thing Sheen Bandasejahtera, Gedung Artha Graha, Kompleks SCBD Jakarta \\ 2 Departemen Pemanfaatan Sumber Daya Perikanan, FPIK, IPB, Jl. Lingkar Kampus, Darmaga - Bogor 16680 \\ ${ }^{*}$ Korespondensi: radarwati@yahoo.com
}

Diterima: 1 Mei 2010; Disetujui: 27 September 2010

\begin{abstract}
Jakarta Bay and its neighbouring waters of Seribu Islands are categorized as fully exploited water areas which theirs coastal areas accomodate multifunction services. Therefore, it needs precautionary approach to manage fisheries activity in that locations. The objectives of this study are to determine optimum allocation of fishing gears and fisheries development areas based on potential fishing gears in Jakarta Bay. The methods used in this study are Linear Goal Programming (LGP) and Locations Quotient (LQ). The result revealed that the potential fishing gears to be developed were pelagic danish seine, drift gillnet, boat lift net, set bottom long line, portable trap and muroami which have the optimum allocation for each fishing gear; 7 units, 98 units, 23 units, 18 units, 8547 units, and 798 units. The potential fishing gears for pelagic danish seine could be developed in Penjaringan and North Seribu Island Districts; drift gillnet could be developed in Cilincing District; boat lift net could be developed in Penjaringan District; set bottom long line could be developed in Penjaringan District; portable trap could be developed in Cilincing and South Seribu Island Districts while muroami could be developed in Penjaringan and South Seribu Island Districts.
\end{abstract}

Key words: optimum allocation, potential fishing gear, development area

\section{ABSTRAK}

Perairan Teluk Jakarta dan perairan sekitarnya Kepulauan Seribu merupakan perairan padat tangkap dimana wilayah pesisirnya mengakomodasi berbagai fungsi pelayan. Oleh karena itu dalam pengelolaannya memerlukan pendekatan yang berprinsip kehati-hatian. Tujuan dari penelitian ini adalah menentukan alokasi optimum dari berbagai alat tangkap dan menentukan wilayah pengembangan perikanan yang berbasis alat tangkap potensial di Teluk Jakarta. Untuk mendukung tujuan tersebut digunakan metode Linear Goal Programming (LGP) dan Location Quotients (LQ). Hasil analisis menunjukkan alat tangkap potensial untuk dikembangkan di Teluk Jakarta terdiri dari payang, jaring insang hanyut, bagan perahu, rawai, bubu, dan muroami dengan alokasi optimal masing-masing 7 unit, 98 unit, 23 unit, 18 unit, 8547 unit, dan 798 unit. Pengembangan payang dapat berbasis di Kecamatan Penjaringan dan di Kecamatan Kepulauan Seribu Utara, jaring insang hanyut dapat berbasis di Kecamatan Cilincing, bagan perahu dapat berbasis di Kecamatan Penjaringan, rawai dapat berbasis di Kecamatan Penjaringan, bubu dapat berbasis di Kecamatan Cilincing dan di Kecamatan Kepulauan Seribu Selatan, muroami dapat berbasis di Kecamatan Penjaringan dan di Kecamatan Kepulauan Seribu Selatan.

Kata kunci: alokasi optimum, alat tangkap potensial, wilayah pengembangan 


\section{PENDAHULUAN}

Perairan Teluk Jakarta memiliki fungsi strategis sebagai perairan ibu kota negara Republik Indonesia dan memiliki berbagai fungsi antara lain sumber penghidupan masyarakat pesisir dan nelayan setempat dari aktivitas perikanan (perikanan tangkap dan budidaya), tempat wisata, konservasi Taman Nasional Laut Kepulauan Seribu (TN (L) Kep. Seribu) hingga lokasi industri non-perikanan di pesisir Teluk Jakarta, namun demikian dengan fungsi yang diembannya, perairan Teluk Jakarta sudah dikategorikan tangkap lebih (Anna 2003), dari sisi lingkungan perairan dikategorikan tercemar oleh limbah sampah, kimia dan minyak (Kusumastanto 2007). Oleh karena itu, Teluk Jakarta perlu dikelola secara berkelanjutan, agar pemanfaatannya dapat berlangsung hingga generasi mendatang.

Teluk Jakarta merupakan bagian dari wilayah pengelolaan perikanan Laut Jawa (WPP. RI 712) dan dibawah pengelolaan adminitratif pemerintah daerah Provinsi DKI Jakarta. Dalam mendukung otonomi daerah, pemerintah daerah melaksanakan pembangunan di setiap sektor yang potensial akan diarahkan untuk dapat mengangkat perekonomian dan kesejahteraan masyarakatnya, termasuk perikanan tangkap di Teluk Jakarta (Muchtar 1999).

Pembangunan sektor perikanan di Teluk Jakarta dihadapkan pada kondisi dimana dalam beberapa tahun terakhir produksi perikanan tangkap secara total tahunan di Teluk Jakarta cenderung menurun (DKPP 2009) dan sejak tahun 2002 produksi ikan nelayan menurun hingga $38 \%$ (Sonari 2009). Bentuk pengelolaan perikanan untuk suatu kondisi tangkap lebih antara lain pemberlakuan kuota (Nikijuluw 2002) dengan menetapkan alokasi optimum untuk alat tangkap di lokasi, sehingga selain dapat tetap menjaga fungsi konservasi di kawasan juga mengurangi pemakaian alat tangkap yang destruktif. Lebih lanjut, setelah penetapan alokasi optimum alat tangkap potensial, kemudian ditetapkan wilayah basis pengembangan alat tangkap. Penetapan wilayah basis ditujukan untuk memicu ekonomi wilayah dan pembangunan sarana dan prasaran perikanan dengan tepat lokasi. Alat tangkap potensial serta mampu mempertahankan keberlanjutan perikanan tangkap adalah alat tangkap yang memenuhi kriteria: teknologi penangkapan ikan ramah lingkungan (TPIRL), jumlah hasil tangkapan tidak melebihi jumlah tangkapan yang diperbolehkan, menguntungkan bagi nelayan, investasi rendah, penggunaan bahan bakar minyak rendah serta memenuhi ketentuan hukum dan perundang-undangan yang berlaku (Monintja 2009).

Dari uraian diatas, tujuan penelitian ini adalah untuk menentukan alokasi optimum dari berbagai jenis alat tangkap potensial di Teluk Jakarta dan menentukan wilayah pengembangan perikanan berbasis alat tangkap potensial dalam mendukung pengelolaan berkelanjutan di Teluk Jakarta.

\section{METODE PENELITIAN}

\section{Lokasi dan waktu penelitian}

Penelitian ini dilaksanakan selama satu tahun dimulai dari bulan Maret 2009 sampai dengan Maret 2010. Tempat penelitian adalah perairan Teluk Jakarta yang merupakan wilayah perairan Kota Jakarta Utara dan Kabupaten Administrasi Kepulauan Seribu, dengan pengamatan di beberapa lokasi yaitu Muara Baru, TPI Muara Kamal, TPI Cilincing, TPI Kali Baru, PPI Muara Angke, Pulau Pramuka dan Pulau Panggang di Kepulauan Seribu.

\section{Jenis Data}

Jenis data yang dikumpulkan dalam penelitian ini terdiri dari data primer dan data sekunder. Data primer mencakup jumlah upaya penangkapan, jumlah hari operasi, jumlah ABK, penggunaan BBM, penggunaan es, penggunaan air tawar, keuntungan dari setiap operasi alat tangkap, frekuensi keikutsertaan dalam penyuluhan konservasi dan penggunaan umpan. Untuk data sekunder mencakup jenis, jumlah, produksi dan sebaran alat tangkap, jumlah nelayan per wilayah dan data sosial ekonomi nelayan.

\section{Metode Pengumpulan Data}

Secara prinsip pengumpulan data dilakukan menggunakan metode survei. Data primer dikumpulkan melalui pengamatan langsung, wawancara dan pengisian kuesioner. Data sekunder dikumpulkan melalui penelusuran berbagai hasil studi, buku/literatur, informasi internet, statistik, terbitan jurnal, media massa, dan bahan seminar.

Wawancara dan pengisian kuesioner dilakukan terhadap responden sebanyak 21 orang yang merupakan wakil dari pihak-pihak yang berkepentingan dengan kegiatan perikanan tangkap khususnya di lokasi. Khusus responden nelayan tangkap dipilih secara purposive berdasarkan ketokohan dalam kelompok dan keaktifan pada kegiatan perikanan tangkap. 


\section{Metode Analisis}

\section{Analisis deskriptif}

Analisis deskriptif kualitatif ditujukan untuk mendapat informasi tentang berbagai kondisi lapang yang bersifat tanggapan dan pandangan seperti jumlah tangkapan, jumlah hari operasi, jumlah nelayan, penggunaan BBM, air, es, umpan buatan, keuntungan, frekuensi penyuluhan konservasi dan penggunaan alat pendukung khusus yang akan dijadikan sasaran (pembatas) pada analisis LGP. Analisis deskriptif juga digunakan untuk penentuan alat tangkap potensial dengan menggunakan analisis statistik sederhana yaitu nilai rata-rata terhadap produksi tahunan alat tangkap diatas 1000 ton per tahun selama kurun waktu 20042008, kemudian dilakukan pemilihan terhadap alat tangkap yang ramah lingkungan dengan tidak menghilangkan alat tangkap yang telah dijadikan program oleh pemerintah daerah.

\section{Analisis Linier Goal Programming (LGP) alokasi alat tangkap}

Menurut Stevenson (1989) bahwa goal programming merupakan variasi dari model linear programming yang dapat digunakan untuk menangani masalah yang mempunyai banyak sasaran. Pada penelitian ini, analisis linier goal programming (LGP) digunakan untuk menentukan alokasi optimum alat tangkap potensial yang dioperasikan di Teluk Jakarta.

Dalam model LGP terdapat dua jenis fungsi matematis, yaitu fungsi tujuan dan fungsi pembatas. Dengan mengacu kepada Siswanto (1990) dan Muslich (1993), model LGP untuk penentuan alokasi optimum dari berbagai alat tangkap yang digunakan di lokasi adalah :

Fungsi tujuan :

$$
Z-\sum_{i=1}^{\infty}(D B i+D A i)
$$

Fungsi pembatas :

$$
\begin{aligned}
& D B_{1}-D A_{1}+a_{11} x_{1}+a_{12} x_{2}+\ldots .+a_{1 n} x_{n}=b_{1} \\
& D B_{2}-D A_{2}+a_{21} x_{1}+a_{22} x_{2}+\ldots .+a_{2 x} x_{x}=b_{2} \\
& D B_{m}-D A_{m}+a_{m 1} x_{1}+a_{m 2} x_{2}+\ldots .+a_{m n} x_{x n}=b_{m}
\end{aligned}
$$

dimana :

$Z=$ Total deviasi yang akan diminimumkan. Total deviasi merupakan penjumlahan dari deviasi fungsi pembatas ke-1 sampai ke-m. Bila total deviasi rendah, berarti deviasi atau simpangan fungsi pembatas dari yang diinginkan juga rendah, dan hal ini yang diharapkan.

$$
\begin{aligned}
& D B_{i}=\text { Deviasi bawah pembatas ke- } i \\
& D A_{i}=\text { Deviasi atas pembatas ke- } i \\
& C j=\text { Parameter fungsi tujuan ke- } j \\
& b_{1}=\text { Kapasitas / ketersediaan pembatas ke- } i \\
& a_{i j}=\text { Parameter fungsi pembatas ke-i pada } \\
& \quad \text { variabel keputusan ke- } j
\end{aligned}
$$

pembatas ke- $i=$ Hasil tangkapan, jumlah hari operasi, jumlah nelayan, penggunaan BBM, penggunaan alat pendukung khusus, penggunaan es, penggunaan air tawar, keuntungan, frekuensi penyuluhan konsevasi dan pengurangan pencemaran oleh umpan ke perairan.

$X j=$ variabel putusan ke-j (jumlah dan alat tangkap)

$X j, D A i$ dan $D B i>0$, untuk $i=1,2, \ldots, m$ dan

$$
j=1,2 \ldots ., n
$$

\section{Analisis Location Quotients (LQ)}

Menurut Moineddin et al. (2002), analisis Location Quotient (LQ) banyak digunakan sebagai metode utama dalam menganalisis ekonomi basis di suatu wilayah Dalam penelitian ini analisis Location Quotients (LQ) digunakan untuk menentukan wilayah (dalam skala kecamatan) yang dapat dijadikan basis pengembangan alat tangkap potensial sehingga dapat memacu ekonomi wilayah Kota Jakarta Utara dan Kabupaten Kepulauan Seribu. Adapun persamaan LQ terkait dengan tujuan penelitian ini dirumuskan :

$$
L Q_{i r}=\frac{e_{i j} / \sum e_{i j}}{E_{i} / \sum E_{i}}
$$

dengan :

$$
\begin{array}{cc}
e_{i j} \quad \begin{array}{c}
\text { output (tenaga kerja) sektor } \mathrm{i} \text { (peri- } \\
\text { kanan) di daerah (kecamatan) } \mathrm{j}
\end{array} \\
\sum e_{i} \quad \begin{array}{c}
\text { total output (tenaga kerja) sektor } \\
\text { perikanan di daerah (kecamatan) } \mathrm{j}
\end{array} \\
E_{i} \quad \begin{array}{c}
\text { output (tenaga kerja) sektor } \mathrm{i} \\
\text { (perikanan) di Kabupaten/Kota }
\end{array} \\
\sum E_{i}=\begin{array}{l}
\text { total output (tenaga kerja) sektor } \\
\text { perikanan di Kabupaten/Kota }
\end{array}
\end{array}
$$

Pengecekan ulang nilai $L Q$ bertujuan untuk mengetahui apakah di lokasi/kecamatan tersebut merupakan wilayah basis yang mendukung pengembangan kegiatan perikanan bagi 
pertumbuhan wilayah. Adapun ketentuannya adalah :

(1) Jika nilai $L Q_{i j}>1$, maka sektor perikanan di lokasi/kecamatan tersebut merupakan sektor basis, sehingga sesuai untuk pengembangan kegiatan perikanan yang mendukung pertumbuhan wilayah.

(2) Jika nilai $L Q_{i j}=1$, maka aktivitas sektor perikanan di lokasi/kecamatan sama dengan aktivitas sektor perikanan tingkat Kabupaten/Kota, menunjukkan keswasembadaan (self-sufficiency) sektor perikanan.

(3) Jika nilai $L Q_{i j}<1$, maka sektor perikanan di lokasi/kecamatan tersebut merupakan sektor non basis, sehingga tidak sesuai untuk pengembangan kegiatan perikanan yang mendukung pertumbuhan wilayah.

Penentuan nilai $L Q$ ini menggunakan output berupa tenaga kerja bidang perikanan tangkap, dalam hal ini adalah nelayan. Profesi nelayan disuatu daerah umumnya sudah memiliki alat tangkap (tradisional), keahlian menangkap ikan, modal yang digunakan untuk melaut atau menangkap ikan (walaupun tidak besar), baik hanya untuk memenuhi kebutuhannya sehari-hari atau untuk diperdagangkan, atau sebagai nelayan pekerja. Pandangan penulis adalah tidak ada suatu daerah yang memiliki penduduk berprofesi nelayan secara turun temurun dimana daerahnya tidak memiliki potensi sumber daya ikan. Seberapa besar tingkat potensi sumber daya ikan tergantung kondisi saat ini, dan dapat berubah baik ke arah pemulihan maupun penurunan stok di masa mendatang. Maka keberadaan nelayan disuatu daerah berawal dari ketersediaan potensi sumber daya ikan. Oleh karena itu penulis berpendapat penentuan nilai LQ menggunakan output tenaga kerja di bidang perikanan tangkap dapat dipenuhi.

Nelayan di Teluk Jakarta, merupakan nelayan yang berkedudukan di pesisir Teluk Jakarta dan Kepulauan Seribu. Sebagaimana secara sosial ekonomi, profesi nelayan sudah melekat sebagai budaya kehidupan bermasyarakatnya. Dengan kondisi Teluk Jakarta yang dikategorikan tangkap lebih (Anna 2003) dan mengalami degradasi lingkungan (Kusumastanto 2007) maka diperlukan penetapan wilayah basis bagi alat tangkap yang termasuk program optimasi.

\section{Analisis pengganda basis dan pertumbuhan tenaga kerja}

Pada analisis ekonomi basis dijumpai permasalahan berupa time lag yang tidak berlangsung secara tepat, yaitu antara respons dari sektor basis terhadap permintaan luar wilayah dan respons dari sektor non basis terhadap perubahan sektor basis. Untuk mengatasi hal ini, maka dilakukan modifikasi rumus penggandaan basis. Rumus penggandaan basis dapat dinyatakan sebagai berikut :

$P b=\frac{N}{N B}$

dengan,

$P b$ = pengganda basis;

$N=$ total tenaga kerja; dan

$N B$ = tenaga kerja sektor basis.

Dengan menggunakan rumus (Glasson 1978), dapat diketahui nilai pengganda tenaga kerja, yaitu menggunakan rumus :

$K=\frac{N}{N B}$

dengan,

$K=$ pengganda tenaga kerja;

$N=$ jumlah tenaga kerja di seluruh sektor; dan

$N B$ = jumlah tenaga kerja di sektor basis.

Dengan menggunakan nilai pengganda tenaga kerja yang telah diperoleh kemudian dikalikan dengan pertumbuhan tenaga kerja di sektor basis didapat angka pertumbuhan tenaga kerja di dalam wilayah. Adapun rumus perhitungannya, adalah :

$\Delta N=\Delta N B \times K$

dengan,

$\Delta N=$ pertumbuhan tenaga kerja di dalam wilayah;

$\triangle N B=$ pertumbuhan tenaga kerja di sektor basis.

\section{HASIL PENELITIAN}

\section{Jenis Alat Tangkap yang Potensial Dikembangkan}

Dari data statistik, jenis alat tangkap di Teluk Jakarta dikelompokkan kedalam 18 jenis alat tangkap, namun yang aktif dioperasikan hanya 13 jenis alat tangkap (termasuk alat tangkap lain-lain) yaitu payang, dogol, pukat cincin, jaring insang hanyut, jaring klitik, jaring insang hanyut, bagan perahu, bagan tancap, rawai, pancing tonda, bubu, muroami, dan lain- 
lain. Hasil analisis deskriptif dengan metode statistik sederhana, terdapat tujuh alat tangkap yang hasil produksi rata-rata tahunannya diatas 1000 ton yaitu payang, pukat cincin, jaring insang hanyut, bagan perahu, rawai tuna, bubu, dan muroami. Hasil tangkapan tahun 2008 dari payang, pukat cincin, jaring insang hanyut, bagan perahu, rawai, bubu, dan muroami pada tahun 2008 berturut-turut adalah 2.558,8 ton, 6.944 ton, 43.698,6 ton, 14.183,3 ton, 4.921 ton, $2.267,4$ ton, dan 1.016,8 ton (DKPP 2009).

Dari tujuh jenis alat tangkap tersebut, pukat cincin termasuk alat tangkap yang tidak ramah lingkungan, sehingga kurang baik untuk dikembangkan, mengingat di perairan Teluk Jakarta terdapat TN (L) Kep. Seribu yang harus dilindungi dari kegiatan penangkapan destruktif. Mengacu pada kondisi tersebut, maka alat tangkap yang potensial dan memungkinkan untuk dikembangkan menjadi enam yaitu: payang, jaring insang hanyut, bagan perahu, rawai, bubu, dan muroami.

Secara umum, identifikasi teknis keenam jenis alat tangkap trsebut sebagai berikut : satu unit payang tersebut mempunyai 2 sayap dengan panjang masing-masing $60 \mathrm{~m}$, badan jaring $10 \mathrm{~m}$, dan kantong $5 \mathrm{~m}$. Satu unit jaring insang hanyut berjumlah 25 piece dengan ukuran mata jaring 2,5 inch, dan tinggi jaring sekitar $20 \mathrm{~m}$. Satu unit bagan perahu mempunyai jaring dengan ukuran $10 \times 10 \mathrm{~m}^{2}$, satu unit bubu ukuran $1,5 \times 0,75 \times 0,5 \mathrm{~m}^{3}$, dan satu unit muroami mempunyai 2 sayap dengan panjang masing-masing $100 \mathrm{~m}$, badan jaring $12 \mathrm{~m}$, dan kantong $8 \mathrm{~m}$. Jumlah alat tangkap pada tahun 2008 adalah payang 712 unit, jaring insang hanyut 960 unit, bagan perahu 553 unit, rawai 2.822 unit, bubu 4.927 unit dan muroami 798 unit.

\section{Optimasi Alokasi Alat Tangkap Potensial}

Hasil analisis deskriptif kualitatif, terdapat sepuluh macam sasaran (pembatas) yang perlu diperhatikan dalam upaya optimasi alokasi jenis alat tangkap potensial di perairan Teluk Jakarta, yaitu : mengoptimumkan hasil tangkapan, jumlah hari operasi, jumlah nelayan, penggunaan BBM, penggunaan alat pendukung khusus, penggunaan es, penggunaan air tawar, keuntungan, frekuensi penyuluhan konservasi dan pengurangan pencemaran oleh umpan ke perairan. Sasaran ini kemudian menjadi pembatas adalam analisis alokasi alat tangkap ini.

Untuk memudahkan analisis, keenam jenis alat tangkap tersebut disimbolkan dengan: X1 = payang, $X 2$ = jaring insang hanyut, $X 3=$ bagan perahu, $X 4=$ rawai, $X 5=$ bubu, dan $X 6=$ muroami. Keenam alat tangkap tersebut kemu- dian menjadi variabel keputusan dalam analisis. Untuk menghindari konflik serta sejalan dengan program pemerintah daerah, maka penentuan alokasi optimum alat tangkap tersebut tidak bersifat meniadakan/mengurangi jenis alat tangkap tertentu yang telah diprogramkan. Sejak tahun 2006, muroami dikembangkan dalam penangkapan ikan di perairan Teluk Jakarta dan sekitarnya. Meskipun bukan alat tangkap paling ramah terhadap lingkungan, tetapi muroami dapat dioperasikan secara pasif, lebih mudah dikuasai oleh masyarakat, dan menyerap tenaga kerja banyak. Pada tahun 2005, jumlah muroami hanya sekitar 75 unit, kemudian meningkat pada tahun 2006, 2007, dan 2008 yaitu masing-masing 641 unit, 641 unit, dan 798 unit. Dengan demikian, kondisi variabel keputusan $\mathrm{X} 1, \mathrm{X} 2, \mathrm{X} 3, \mathrm{X} 4, \mathrm{X} 5$, dan $\mathrm{X} 6$ adalah $\mathrm{X} 1>=0, \mathrm{X} 2>=0, \mathrm{X} 3>=0, \mathrm{X} 4$ $>=0, X 5>=0, X 6>=798$.

Dalam optimasi ini penulis mengembangkan dalam dua skenario, yaitu optimasi dengan dipenuhinya kesepuluh sasaran/pembatas secara bersamaan (Skenario I) dan optimasi dengan dipenuhinya sasaran/ pembatas secara bertahap berdasarkan prioritas/kepentingannya (Skenario II). Untuk skenario II, pemenuhan sasaran dibagi dalam dua kelompok berdasarkan pengamatan di lokasi dan wawancara dengan responden terlatih :

(1) Kelompok I (sasaran yang diprioritaskan dipenuhi): mengoptimumkan hasil tangkapan, jumlah hari operasi, jumlah nelayan, penggunaan BBM dan frekuensi penyuluhan konservasi

(2) Kelompok II (sasaran dipenuhi pada analisis tahap berikutnya): mengoptimumkan penggunaan alat pendukung khusus, penggunaan es, penggunaan air tawar, keuntungan dan pengurangan pencemaran oleh umpan ke perairan.

\section{Alokasi Optimum Alat Tangkap di Teluk Jakarta}

Optimasi keenam alat tangkap tersebut menggunakan skenario I dan skenario II tersebut sebagai berikut :

\begin{tabular}{l} 
Hasil analisis LINDO skenario I: \\
\multicolumn{3}{l}{ LP OPTIMUM FOUND AT STEP 6} \\
\multicolumn{3}{c}{ OBJECTIVE FUNCTION VALUE } \\
$\begin{array}{ccc}\text { 1) } \quad 0.3981288 E+11 \\
\text { VARIABLE } & \text { VALUE } & \text { REDUCED COST } \\
\text { DA1 } & 0.000000 & 1750001.000000 \\
\text { DA2 } & 0.000000 & 1.000000 \\
\text { DA3 } & 0.000000 & 1.000000 \\
\text { DA4 } & 0.000000 & 1.000000 \\
\text { DA5 } & 0.000000 & 1.000000\end{array}$
\end{tabular}




$\begin{array}{cll}\text { DA6 } & 0.000000 & 1.000000 \\ \text { DA7 } & 0.000000 & 1.000000 \\ \text { DB8 } & * \star * * * * \star * * * * * & 0.000000 \\ \text { DB9 } & 0.000000 & 1.000000 \\ \text { DB10 } & 0.000000 & 1.000000 \\ \text { X1 } & 0.000000 & 0.000000 \\ \text { X2 } & 47.741276 & 0.000000 \\ \text { X3 } & 27.016666 & 0.000000 \\ \text { X4 } & 117.716049 & 0.000000 \\ \text { X5 } & 8500.641602 & 0.000000 \\ \text { X6 } & 798.000000 & 0.000000\end{array}$

Hasil analisis LINDO skenario II : LP OPTIMUM FOUND AT STEP 7 OBJECTIVE FUNCTION VALUE 1) $0.3981288 \mathrm{E}+11$

$\begin{array}{clc}\text { VARIABLE } & \text { VALUE } & \text { REDUCED COST } \\ \text { DA1 } & 0.000000 & 1.000000 \\ \text { DA2 } & 0.000000 & 1.000000 \\ \text { DA3 } & 0.000000 & 1.000000 \\ \text { DA4 } & 0.000000 & 1.000000 \\ \text { DA5 } & 0.000000 & 1.000000 \\ \text { DA6 } & 0.000000 & 1.000000 \\ \text { DA7 } & 0.000000 & 1.000000 \\ \text { DB8 } & * * * * * * * * * * & 0.000000 \\ \text { DB9 } & 0.000000 & 1.000000 \\ \text { DB10 } & 0.000000 & 1.000000 \\ \text { X1 } & 6.743933 & 0.000000 \\ \text { X2 } & 97.963364 & 0.000000 \\ \text { X3 } & 23.419903 & 0.000000 \\ \text { X4 } & 17.626667 & 0.000000 \\ \text { X5 } & 8547.314453 & 0.000000 \\ \text { X6 } & 798.000000 & 0.000000\end{array}$

Berdasarkan hasil analisis tersebut, alokasi optimum payang, jaring insang hanyut, bagan perahu, rawai, bubu, dan muroami menggunakan skenario I berturut-turut adalah 0 unit, 48 unit, 27 unit, 118 unit, 8501 unit, dan 798 unit. Sedangkan alokasi payang, jaring insang hanyut, bagan perahu, rawai, bubu, dan muroami menggunakan skenario II berturutturut adalah 7 unit, 98 unit, 23 unit, 18 unit, 8547 unit, dan 798 unit. Ukuran teknis setiap unit alat tangkap tersebut sama dengan yang dijelaskan pada Bagian 3.1.

\section{Wilayah Basis Pengembangan Alat Tangkap Potensial}

Dalam upaya optimasi pengembangan keenam alat tangkap potensial yang dihasilkan pada analisis sebelumnya, lebih lanjut dilakukan penentuan wilayah basis pengembangan alat tangkap. Penentuan wilayah basis, bertujuan agar nelayan yang sudah ada diberdayakan sesuai keberadaan di suatu kecamaan. Selain itu, penentuan wilayah basis alat tangkap juga penting berkaitan dengan pembangunan sarana dan prasarana yang dibutuhkan di lokasi (tepat lokasi) dan dapat dimanfaatkan secara optimal (sesuai kebutuhan). Sebagai contoh, hasil penelitian di lokasi daerah Marunda, Kecamatan Cilincing, banyak terdapat nelayan, namun tidak memiliki sarana prasarana yang memadai karena yang disediakan oleh pemerintah saat ini di TPI Cilincing dan TPI Kali Baru. Selama ini nelayan Marunda mendaratkan ikannya di kedua TPI tersebut diatas, namun basis kapal penangkap ikan tetap di Marunda. Kondisi seperti itu berkaitan dengan biaya operasional kapal, nelayan Marunda harus menempuh lebih jauh perjalanan untuk mendaratkan ikannya di Cilincing/Kalibaru dibanding di Marunda.

Analisis Location Quotients (LQ) yang dilakukan dalam penelitian ini menentukan wilayah basis dari pengembangan alat tangkap potensial dan penentuan alokasi pengembangan daerah secara terarah yang pada akhirnya memacu pertumbuhan ekonomi wilayah Kota Jakarta Utara dan Kabupaten Kepulauan Seribu, sebagaimana Hood (1998) LQ adalah suatu alat pengembangan ekonomi dimana tekni LQ merupakan satu pendekantan umum dalam model ekonomi basis sebagai langkah awal memahami sektor kegiatan yang memicu pertumbuhan ekonomi.

\section{Nilai LQ wilayah}

Wilayah Kota Jakarta Utara terbagi dalam enam kecamatan, yaitu Kecamatan Penjaringan, Pademangan, Tanjung Priok, Koja, Cilincing, dan Kelapa Gading. Sebaran tenaga kerja dan hasil analisis LQ di wilayah kota Jakarta Utara dapat dilihat pada Tabel 1 dan 2. Tabel 2 menunjukkan bahwa di Keca-matan Priok dan Kelapa Gading tidak dijadikan wilayah basis alat tangkap apapun, dikarenakan tidak tersedianya tenaga kerja di kedua kecamatan itu.

Wilayah Kabupaten Adm. Kepulauan Seribu terbagi menjadi dua kecamatan, yaitu Kecamatan Kepulauan Seribu Utara dan Kepulauan Seribu Selatan. Secara umum, penduduk Kecamatan Kepulauan Seribu Selatan lebih banyak daripada Kecamatan Kepulauan Seribu Utara, dan pusat pemerintahan Kabupaten Adm. Kepulauan Seribu terdapat di Kecamatan Kepulauan Seribu Selatan, tepatnya di Pulau Pramuka, namun sektor perikanan berkembang cukup merata di kedua kecamatan tersebut. Sebaran tenaga kerja dan hasil analisis LQ di wilayah Kabupaten Kepulauan Seribu dapat dilihat pada Tabel 3 dan 4. Hasil analisis LQ bagi pengembangan payang, jaring insang hanyut, bagan perahu, rawai, bubu, dan muroami di wilayah Kabupaten Administratif Kepulauan Seribu disajikan pada Tabel 4. 


\section{Pertumbuhan tenaga kerja}

Terhadap hasil analisis LQ Tabel 2 dan 4, dilakukan perhitungan lanjut untuk nilai pengganda tenaga kerja $(\mathrm{K})$ untuk usaha perikanan di setiap Kecamatan dengan nilai $L Q>1$. Berdasarkan analisis yang dilakukan, didapatkan nilai pengganda tenaga kerja (K) untuk payang, bagan perahu, rawai di Kecamatan
Penjaringan berturut-turut adalah 32,80, 7,25, dan 1,58 , nilai pengganda tenaga kerja $(K)$ untuk rawai di Kecamatan Pademangan adalah 1,09 , nilai pengganda tenaga kerja $(K)$ untuk bubu di Kecamatan Koja adalah 1,91, dan nilai pengganda tenaga kerja $(\mathrm{K})$ untuk jaring insang hanyut dan bubu di Kecamatan Cilincing adalah 2,69 dan 11,96.

Tabel 1. Sebaran tenaga kerja / nelayan di wilayah Kota Jakarta Utara

\begin{tabular}{|c|c|c|c|c|c|c|c|}
\hline $\begin{array}{c}\text { Alat } \\
\text { tangkap } \\
\text { potensial }\end{array}$ & $\begin{array}{c}\text { Kec. } \\
\text { Penja- } \\
\text { ringan }\end{array}$ & $\begin{array}{c}\text { Kec. } \\
\text { Pade- } \\
\text { mangan }\end{array}$ & $\begin{array}{c}\text { Kec. Tj. } \\
\text { Priok }\end{array}$ & $\begin{array}{c}\text { Kec. } \\
\text { Koja }\end{array}$ & $\begin{array}{c}\text { Kec. } \\
\text { Cilin- } \\
\text { cing }\end{array}$ & $\begin{array}{c}\text { Kec. } \\
\text { Kelapa } \\
\text { Gading }\end{array}$ & Total \\
\hline $\begin{array}{c}\text { Payang } \\
\text { (X1) }\end{array}$ & 340 & 2 & 0 & 3 & 151 & 0 & 496 \\
\hline $\begin{array}{c}\text { Jaring } \\
\text { Insang } \\
\text { Hanyut } \\
\text { (X2) }\end{array}$ & 1789 & 35 & 0 & 31 & 3136 & 0 & 4991 \\
\hline $\begin{array}{c}\text { Bagan } \\
\text { Perahu } \\
\text { (X3) }\end{array}$ & 1539 & 0 & 0 & 16 & 961 & 0 & 2516 \\
\hline $\begin{array}{c}\text { Rawai } \\
\text { (X4) }\end{array}$ & 7058 & 449 & 0 & 12 & 3484 & 0 & 11003 \\
\hline Bubu (X5) & 422 & 5 & 0 & 68 & 706 & 0 & 8 \\
\hline $\begin{array}{c}\text { Muroami } \\
\text { (X6) }\end{array}$ & 5 & 0 & 0 & 0 & 3 & 0 & 8 \\
\hline Total & 11153 & 491 & 0 & 130 & 8441 & 0 & 20215 \\
\hline
\end{tabular}

Tabel 2. Hasil analisis LQ wilayah Kota Jakarta Utara

\begin{tabular}{|l|c|c|c|c|c|c|}
\hline \multirow{2}{*}{$\begin{array}{c}\text { Alat Tangkap } \\
\text { Potensial }\end{array}$} & \multicolumn{7}{|c|}{ Nilai LQ } \\
\cline { 2 - 7 } & $\begin{array}{c}\text { Kec. } \\
\text { Penjaringan }\end{array}$ & $\begin{array}{c}\text { Kec. } \\
\text { Pademangar }\end{array}$ & $\begin{array}{c}\text { Kec. } \\
\text { Tj. Priok }\end{array}$ & Kec. Koja & $\begin{array}{c}\text { Kec. } \\
\text { Cilincing }\end{array}$ & $\begin{array}{c}\text { Kec. Kelapa } \\
\text { Gading }\end{array}$ \\
\hline Payang (X1) & 1.24 & 0.17 & - & 0.94 & 0.73 & - \\
\hline $\begin{array}{l}\text { Jaring insang } \\
\text { hanyut (X2) }\end{array}$ & 0.65 & 0.29 & - & 0.97 & 1.50 & - \\
\hline $\begin{array}{l}\text { Bagan perahu } \\
\text { (X3) }\end{array}$ & 1.11 & 0.00 & - & 0.99 & 0.91 & - \\
\hline Rawai (X4) & 1.16 & 1.68 & - & 0.17 & 0.76 & - \\
\hline Bubu (X5) & 0.64 & 0.17 & - & 8.80 & 1.41 & - \\
\hline Muroami (X6) & 1.16 & 0.00 & - & 0.00 & 0.92 & - \\
\hline
\end{tabular}

Tabel 3. Sebaran tenaga kerja / nelayan di wilayah Kabupaten Kepulauan Seribu

\begin{tabular}{|c|c|c|c|}
\hline \multirow[b]{2}{*}{$\begin{array}{l}\text { Sektor Perikanan / Alat } \\
\text { Tangkap Potensial }\end{array}$} & \multicolumn{3}{|c|}{ Jumlah Tenaga Kerja / Nelayan (orang) } \\
\hline & $\begin{array}{l}\text { Kep. Seribu } \\
\text { Selatan }\end{array}$ & Kep. Seribu Utara & $\begin{array}{c}\text { Total Kab. Kep. } \\
\text { Seribu }\end{array}$ \\
\hline Payang (X1) & 2480 & 1561 & 4041 \\
\hline Jaring Insang Hanyut (X2) & 0 & 0 & 0 \\
\hline Bagan Perahu (X3) & 0 & 0 & 0 \\
\hline Rawai (X4) & 0 & 0 & 0 \\
\hline Bubu (X5) & 429 & 764 & 1193 \\
\hline Muroami (X6) & 1699 & 2943 & 4642 \\
\hline Total & 4608 & 5268 & 9876 \\
\hline
\end{tabular}


Tabel 4. Hasil analisis LQ wilayah Kabupaten Adm. Kepulauan Seribu

\begin{tabular}{|c|c|c|}
\hline \multirow[b]{2}{*}{ Alat Tangkap Potensial } & \multicolumn{2}{|c|}{ Nilai LQ } \\
\hline & Kec. Kep. Seribu Utara & Kec. Kep. Seribu Selatan \\
\hline Payang (X1) & 1.32 & 0.72 \\
\hline Jaring Insang Hanyut (X2) & - & - \\
\hline Bagan Perahu (X3) & - & - \\
\hline Rawai (X4) & - & - \\
\hline Bubu (X5) & 0.77 & 1.20 \\
\hline Muroami (X6) & 0.78 & 1.19 \\
\hline \multirow[b]{2}{*}{ Alat Tangkap Potensial } & \multicolumn{2}{|c|}{ Nilai LQ } \\
\hline & Kec. Kep. Seribu Utara & Kec. Kep. Seribu Selatan \\
\hline Payang (X1) & 1.32 & 0.72 \\
\hline Jaring Insang Hanyut (X2) & - & - \\
\hline Bagan Perahu (X3) & - & - \\
\hline Rawai (X4) & - & - \\
\hline Bubu (X5) & 0.77 & 1.20 \\
\hline Muroami (X6) & 0.78 & 1.19 \\
\hline
\end{tabular}

Nilai pengganda tenaga kerja tersebut diatas artinya: setiap kenaikan satu tenaga kerja untuk alat tangkap potensial tertentu di satu kecamatan akan meningkatkan tenaga kerja di kecamatan tersebut sebesar nilai penggandanya (bila hasilnya adalah bilangan desimal maka di bulatkan ke bawah untuk nilai desimal kurang dari 0.5 dan dibulatkan ke atas jika nilai desimal lebih atau sama dengan 0,5). Contoh untuk alat tangkap payang di kecamatan Penjaringan, nilai pengganda tenaga kerjanya adalah 32,8 artinya setiap kenaikan satu tenaga kerja untuk alat tangkap payang di kecamatan Penjaringan akan meningkatkan tenaga kerja di kecamatan Penjaringan sebanyak 33 orang.

Hasil analisis yang dilakukan menunjukkan bahwa pertumbuhan tenaga kerja di wilayah Kecamatan Penjaringan dari kontribusi sektor perikanan, alat tangkap payang, bagan perahu, rawai berturut-turut adalah 502 orang/ tahun, 468 orang/tahun, 424 orang/tahun. Pertumbuhan tenaga kerja di wilayah Kecamatan Pademangan dari kontribusi sektor perikanan, alat tangkap rawai adalah 20 orang/tahun. Pertumbuhan tenaga kerja di wilayah Kecamatan Koja dari kontribusi sektor perikanan, alat tangkap bubu 4 orang/tahun. Pertumbuhan tenaga kerja di wilayah Kecamatan Cilincing dari kontribusi sektor perikanan, alat tangkap jaring insang hanyut dan bubu adalah 401 orang/ tahun dan 388 orang/tahun.

Pertumbuhan tenaga kerja di wilayah Kecamatan Kepulauan Seribu Selatan kontribusi sektor perikanan, alat tangkap payang adalah 286 orang/tahun, dan pertumbuhan tenaga kerja di wilayah Kecamatan Kepulauan Seribu Utara kontribusi sektor perikanan, alat tangkap muroami dan bubu adalah 385 orang/tahun dan 485 orang/tahun.

\section{Skenario Pengembangan Alat Tangkap Potensial}

Mengacu kepada hasil analisis optimasi, alat tangkap yang ada saat ini (payang, jaring insang hanyut, bagan perahu dan rawai) dianjurkan untuk dikurangi. Pengurangan alat tangkap aktif selaras dengan keberadaan kawasan konservasi Taman Nasional Laut Kepulauan Seribu agar membatasi aktivitas pemanfaatan SDI di sekitarnya. Optimasi alokasi alat tangkap menggunakan skenario II, payang tidak dihilangkan $100 \%$ seperti pada skenario I. Hal ini karena pada skenario II pemenuhan sasaran/pembatas dilakukan secara bertahap, sehingga dapat mengurangi dampak sosial akibat pengaturan tersebut. Alat tangkap yang dipertahankan lebih banyak dan jumlah nelayan yang terkena pengaturan akan lebih sedikit. Skenario II lebih tepat untuk kondisi sumber daya yang terbatas sehingga dalam aplikasi di lapangan lebih aman. Cochrane (2002) menyatakan bahwa kegiatan pengelolaan sumber daya perikanan harus menjadikan kelestarian sumber daya dan kepentingan masyarakat lokal sebagai tujuan akhir dari kegiatan pengelolaan.

\section{Wilayah Pengembangan Alat Tangkap Potensial}

Berdasarkan Tabel 2, kontribusi dari sektor perikanan untuk alat tangkap payang, bagan perahu, rawai dan muroami di Kecamatan Penjaringan mempunyai $L Q>1$, yaitu masingmasing 1,24, 1,11, 1,16, dan 1,16. Dengan demikian, Kecamatan Penjaringan dapat menjadi basis bagi pengembangan alat tangkap potensial payang, bagan perahu, rawai dan muroami di Jakarta Utara. Untuk mendukung hal ini, maka menurut Sunarto et al. (1997) lokasi-lokasi 
yang menjadi pusat kegiatan perikanan di Kecamatan Penjaringan seperti TPI Kamal Muara dan TPI Muara Angke perlu dibenahi dan dilengkapi dengan berbagai sarana dan prasarana untuk mendukung operasi keempat alat tangkap potensial tersebut, termasuk sarana dan kegiatan pengembangan keahlian nelayan/ tenaga kerja. Kecamatan Pademangan sebenarnya dapat menjadi basis pengembangan rawai (nilai $\mathrm{LQ}=1,68$ (lebih tinggi dari 1 ). Namun karena sebaran tenaga kerja/nelayannya (449 orang) lebih sedikit daripada Kecamatan Penjaringan (7058 orang), maka dukungan pengembangannya kurang kuat. Hal yang sama juga terjadi pada Kecamatan Koja dalam pengembangan bubu, dimana jumlah nelayannya lebih sedikit daripada nelayan Kecamatan Cilincing. Kecamatan Tanjung Priok dan Kecamatan Kelapa Gading tidak menjadi basis pengembangan alat tangkap potensial manapun, karena tenaga kerja/nelayan tidak terdapat di kedua kecamatan tersebut.

Kecamatan Cilincing dapat menjadi basis pengembangan perikanan alat tangkap jaring insang hanyut dan bubu karena mempunyai $L Q$ $>1$, yaitu masing-masing 1,50 dan 1,41. Dilihat dari output, maka jumlah tenaga kerja yang menekuni jaring insang hanyut dan bubu di Kecamatan Cilincing relatif banyak dibandingkan wilayah lainnya, yaitu 3136 orang dan 706 orang. Terkait dengan ini, maka lokasi perikanan tangkap di Kecamatan Cilincing seperti TPI Cilincing, TPI Kalibaru, dan TPI Cakung Dalam dapat dioptimumkan perannya sehingga mendukung pengembangan kedua wilayah tersebut. Berbagai kebutuhan terkait operasi jaring insang hanyut dan bubu harus dapat disiapkan oleh unit-unit usaha pendukung yang terdapat di Kecamatan Cilincing.

Berdasarkan Tabel 4, di Kecamatan Kepulauan Seribu Utara dapat menjadi basis pengembangan alat tangkap payang ( $L Q=$ 1,32). Hal ini didukung oleh jumlah nelayan yang lebih banyak (4608 orang) dibanding nelayan di Kecamatan Kepulauan Seribu Selatan (1561 orang) dan sebesar 53,82\% dari total nelayan tersebut mengoperasikan alat tangkap payang.

Kecamatan Kepulauan Seribu Selatan menjadi basis pengembangan alat tangkap bubu dan muroami dengan $L Q>1$ yaitu masingmasing 1,20 dan 1,19. Nelayan bubu dan muroami di Kecamatan Kepulauan Seribu Selatan hampir 59,08 \% dari total jumlah nelayan (9876 orang). Penentuan wilayah basis di kecamatan ini didukung dengan keberadaan PPI Pulau Pramuka untuk pendaratan ikan, pemasaran, pelelangan dan distribusi ke Kota Jakarta.

\section{Pertumbuhan Wilayah}

Dari hasil analisis tersebut, terlihat bahwa pertumbuhan tenaga kerja perikanan cukup tinggi di wilayah Jakarta Utara, kecuali untuk alat tangkap rawai di kecamatan Pademangan dan bubu di Kecamatan Koja. Rendahnya pertumbuhan ini lebih disebabkan oleh minimnya kegiatan perikanan di kedua kecamatan tersebut sehingga tidak memacu pertumbuhan kegiatan perikanan. Pertumbuhan tenaga kerja cukup tinggi di semua wilayah di Kepulauan Seribu. Bila alat tangkap potensial dikembangkan pada wilayah yang sesuai, yaitu payang di wilayah Kecamatan Kepulauan Seribu Utara, serta muroami dan bubu di wilayah Kecamatan Kepulauan Seribu Selatan, akan mendukung pertumbuhan ekonomi masyarakat di kedua wilayah tersebut.

\section{KESIMPULAN DAN SARAN}

\section{Kesimpulan}

Alat tangkap yang potensial untuk dikembangkan di Teluk Jakarta terdiri dari payang, jaring insang hanyut, bagan perahu, rawai, bubu, dan muroami dengan alokasi optimum masing-masing 7 unit, 98 unit, 23 unit, 18 unit, 8547 unit, dan 798 unit. Untuk mendukung keberlanjutan perikanan tangkap di wilayah Teluk Jakarta, maka pengembangan payang dapat berbasis di Kecamatan Penjaringan dan Kecamatan Kepulauan Seribu Utara, jaring insang hanyut dapat berbasis Kecamatan Cilincing, bagan perahu dapat berbasis di Kecamatan Penjaringan, rawai dapat berbasis Kecamatan Penjaringan, bubu dapat berbasis di Kecamatan Cilincing dan Kecamatan Kepulauan Seribu Selatan, dan muroami dapat berbasis di Kecamatan Penjaringan dan Kecamatan Kepulauan Seribu Selatan.

\section{Saran}

Realisasi alokasi optimum alat tangkap hendaklah dilakukan secara bertahap dan memperhatikan kelangsungan ekonomi masyarakat nelayan, sehingga tidak terjadi konflik sosial yang serius dan dapat mengancam fungsi konservasi di perairan Teluk Jakarta. Pembangunan sarana dan prasarana perikanan di Teluk Jakarta hendaknya disesuaikan dengan penetapan wilayah basis pengembangan alat tangkap, sehingga lebih berguna bagi pengembangan perikanan tangkap di lokasi.

Perlu dilakukan kajian lebih lanjut terhadap alat tangkap muroami telah ditetapkan sejak tahun 2006 sebagai program pemerintah daerah Provinsi DKI Jakarta untuk dikembang- 
kan, mengingat pola operasi yang rentan berinteraksi dengan terumbu karang.

\section{DAFTAR PUSTAKA}

Anna S. 2003. Model Embedded Dinamik Ekonomi Interaksi Perikanan Pencemaran. [disertasi]. Bogor : Program Pascasarjana, Institut Pertanian Bogor. 388 hal.

Budiharsono S. 2001. Teknik Analisis Pembangunan Wilayah Pesisir dan Lautan. Pradnya Paramita. Jakarta. 159 hal.

Cochrane KL. 2002. A Fishery Manager's Guidebook. Management Measures and Their Application. Senior Fishery Resources Officer. Fishery Resources Division. FAO Fisheries Department. Rome. $231 \mathrm{p}$.

[DKPP] Dinas Kelautan dan Pertanian Provinsi DKI Jakarta. 2009. Data Perikanan DKI Jakarta tahun 1992 - 2008. Jakarta.

Hood R. 1998. Economic Analysis : A Location Quotient. Primer. Principal Sun Region Associates, Inc.

Isserman AM. 1977. The Location Quotient Approach to Estimating Regional Economic Impacts. Journal of the American Institute of Planners 43, 33-41.

Kusumastanto T. 2007. Pendekatan Integrated River Basin, Coastal and Ocean Management (IRCOM) Menuju Pembangunan Berkelanjutan : Studi Kasus Pengelolaan Ekosistem Pesisir dan Laut Teluk Jakarta dan Kepulauan Seribu. Bogor. PKSPL-IPB : http://tridoyo.blogspot.com/ 2007/09/pendekatanintegrated-riverbasin .html [4 Sep 2009]
Moineddin R, Beyene J, Boyle E. 2002. On the Location Quotient Confidence Interval. Geographical Analysis 35(3). The Ohio University. USA.

Monintja 2009. Tata Laksana untuk Perikanan yang Bertanggung Jawab. Laboratorium Teknologi Penangkapan Ikan. FPIK. IPB. Bogor

Muchtar A. 1999. Kebijakaan Pengembangan Perikanan Laut di Indonesia dalam Prosiding Seminar Tentang Oseanologi dan IImu Lingkungan Laut. Puslitbang Oseanografi LIPI. Jakarta. Hal : 1-7

Muslich M. 1993. Metode Kuantitatif. Lembaga Penerbit Fakultas Ekonomi Universitas Indonesia. Jakarta. 445 hal.

Nikijuluw VPH. 2002. Rezim Pengelolaan Sumber daya Perikanan. P3R. Jakarta.

Siswanto. 1990. Sistem Komputer Manajemen LINDO. Penerbit PT Elex Media Komputindo. Kelompok Gramedia. Jakarta. 242 hal.

Sonari SS. 17 Jul 2009. Bom Waktu Pencemaran Teluk Jakarta dan Pulau Seribu. Republika: http://www.oseanografi.lipi. go.id/index [20 Jul 2009]

Sunarto K, Sutikno, Dulbahri. 1997. Kesesuaian Wilayah Perairan Laut untuk Budidaya Rumput Laut Jenis Eucheuma di Terumbu Karang Pulau Pari Teluk Jakarta. Geomatika. No. 1-2 hal 18-33.

Stevenson WJ. 1989. Introduction of Management Science. Richard D. Irwin Inc. USA. 